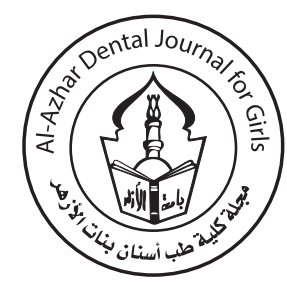

\title{
Evaluation of the effect of endodontic chelating solutions on push out bond strength of endodontic sealers (An in-vitro study)
}

\author{
Mai Mohamed Salah El-Din ${ }^{(1)}$, Mohsen Nour El-Din ${ }^{(2)}$ and Mahmoud Hassan Mohamed ${ }^{(3)}$
}

Codex : 43/1810

azhardentj@azhar.edu.eg

http://adjg.journals.ekb.eg

\section{KEYWORDS}

AH Plus,

$\mathrm{ZnO}$ nanosealer,

push-out bond strength

\begin{abstract}
Aim: This study was carried out to evaluate the effect of various chelating solutions (EDTA-Apple Vinegar-Sodium Hypochlorite)on the radicular push-out bond strength of zinc oxide nanosealer and AH Plus resin based rootcanal sealer. Materials and Methods: 180 extracted single-rooted human teeth with complete roots, fully formed apices were used in this study,on completion of instrumentation, the specimens will be randomly divided into three groups $(\mathrm{n}=60)$ according to chelating solution applied: Group ( I ) $1.5 \mathrm{~mL}$ of $17 \%$ EDTA (pH = 7), Group ( II ) $2.5 \mathrm{~mL}$ of vinegar apple and Group ( III ) $2 \mathrm{~mL}$ of $5.25 \%$ sodium hypochlorite $(\mathrm{NaOCl})$. These groups are subdivided into two subgroups $(n=30)$ each according to root canal sealer used: Subgroup A: AH Plus and Subgroup B: Zinc oxide nanosealer. Then the specimens in the subgroups will be further randomly divided into two groups $(n=15)$ according to storage time: Subgroup 1:one week storage time and Subgroup 2: one month storage time The root canals were prepared using ProTaper rotary instruments up to master apical rotary size F3 (\#30), in conjunction with $2 \mathrm{~mL}$ of Normal saline solution (Sodium Chloride 0.9\%) irrigation between each file and the chelating solution was applied for 1 minute then final rinse with distilled water. The sealers were loaded and introduced to the canal using $\mathrm{K}$ file size40.Testing push-out bond strength was done for all samples using the Intrson universal testing machine. Results: It was found that the highest push-out bond strength mean value recorded for (EDTA+ AH Plus) (1 week) group (IA1) (3.424 MPa) followed by (Apple Vinegar+ AH Plus) (1 week) group (IIA1) (1.263 MPa) while the lowest mean value recorded for $(\mathrm{NaOCl}+\mathrm{ZnO}$ nanosealer) $(1$ month) group (IIIb2) (0.575 MPa). The difference between different groups was statistically significant as revealed with one way ANOVA test $(\mathrm{p}<0.05)$. Tukey's post-hoc test showed non-significant $(\mathrm{p}>0.05)$ differences between $\{($ Apple Vinegar+AH Plus $)$ and (NaOCl +AH Plus) (1 week) $\},\{($ EDTA+ AH Plus), (Apple Vinegar+ AH Plus) and
\end{abstract}

Paper extracted from thesis entitled: " Evaluation of the effect of endodontic chelating solutions on push-out bind strength of endodontic sealers "(An in-vitro Study)".

1. Dentist at Ministry of Health, Egypt.

2. Professor of Endodontics, Faculty of Dental Medicine for girls, Al-Azhar University.

3. Professor and Head of Endodontic department, Faculty of Dental Medicine for Boys, Al Azhar University, Assuit branch. 
$(\mathrm{NaOCl}+\mathrm{AH}$ Plus $)(1$ month $)\},\{($ EDTA $+\mathrm{ZnO}$ nanosealer $)$ and (NaOCl+ $\mathrm{ZnO}$ nanosealer) (1 month) . Conclusions: AH Plus sealer had the highest push-out bond strength when used with EDTA, ZnO nanosealer had the highest push -out when used with apple vinegar and all AH Plus subgroups had higher pushout bond strength than $\mathrm{ZnO}$ nanosealers subgroups

\section{INTRODUCTION}

The action of endodontic instruments associated with the irrigant solution during the biomechanical preparation stage favors cleaning and disinfection of root canal systems, eliminating aggressive and irritant agents such as microorganisms and pulp tissue residues. However, the instrument in contact with the root canal walls causes formation of the smear layer. ${ }^{(1,2)}$

Whenever dentin is cut using hand or rotary instruments, the mineralized tissues are not shredded or cleaved but shattered to produce considerable quantities of debris. Much of this, made up of very small particles of mineralized collagen matrix, is spread over the surface to form what is called the smear layer. Identification of the smear layer was made possible using the electron microprobe with scanning electron microscope (SEM) attachment ${ }^{(3)}$. The smear layer was made of particles ranging in size from less than $0.5-15 \mu \mathrm{m}$. Scanning electron microscope studies of cavity preparations demonstrated a thin layer of grinding debris. It is estimated it to be $2-5 \mu \mathrm{m}$ thick, extending a few micrometres into the dentinal tubules. ${ }^{(4)}$

Sodium hypochlorite $(\mathrm{NaOCl})$ is one of the most widely used endodontic irrigants for the chemomechanical preparation of root canals because of its excellent antimicrobial action and capacity of dissolving organic materials ${ }^{(5)}$, which increase directly with the increase of the concentration. ${ }^{(6)}$

The use of ethylenediamine tetra-acetic acid (EDTA) is usually recommended to remove the smear layer. This substance is a weak acid with chelating action and concomitant protein denaturing, which promotes the increase in dental permeability facilitating the action of the intracanal medication (7) and the bond between dentin and endodontic cements. ${ }^{(8)}$

More recently, the use of apple vinegar as an auxiliary solution in the chemomechanical preparation of root canals has also been investigated and deserves attention due to the promising results obtained when compared to traditional endodontic irrigants, such as $\mathrm{NaOCl}$ and EDTA ${ }^{(9)}$.As it has proven antimicrobial action, reduces dentinal microhardness ${ }^{(10)}$, in addition to removing the smear layer ${ }^{(11,12)}$, It is a combination of acetic, citric, formic, lactic, succinic (succinate), and tartaric acids with small quantities of alcohol resulting from the fermentation process and it is responsible for reducing the surface tension of the solution. However, the highest acid concentrations of the vinegar are represented by the acetic $(5 \%)$ and malic $(0.35 \%)$ acids. ${ }^{(13)}$

The main objective of every root canal filling is to achieve a high degree of tightness. The quality of the root canal filling directly depends on the shrinkage upon setting and the solubility of the material used, as these properties are decisive for the impermeability of the treated root canal. Epoxy resin sealers have been used because of their reduced solubility ${ }^{(14)}$, apical seal and micro-retention to root dentine. ${ }^{(15)}$

With AH Plus, a new material was created which, is characterised by very low shrinkage or, in other words, by high dimensional stability. A further physical parameter which can also be decisive with regard to the tightness of the root canal filling is the particle size of the fillers used. Therefore, finely ground calcium tungstate with an average particle size of $8 \mathrm{~mm}$ (in relation to the mass) and finely ground zirconium oxide with an average particle size of $1.5 \mathrm{~mm}$ are used as fillers. The particle size of the filler has a decisive effect on the film thickness of the mixed material. AH Plus has a film 
thickness of $26 \mathrm{~mm}$, which is clearly below the value of less than $50 \mathrm{~mm}$ required by the ISO standard for root canal sealing materials (ISO 6876)..$^{(16)}$

Also recently, there is a new experimental endodontic sealer (nano-powder $\mathrm{ZnO}$ ) This sealer is similar to various ZOE-based sealers, but with different sizes of nano-particles of zinc oxide.Zinc oxide is an environment-friendly material which has been used widely in medical applications such as cancer treatment and DNA detection. In addition, Zinc oxide has interesting antibacterial properties, so its powder can be used for dental applications as a sealer ${ }^{(17,18,19)}$.

This study, therefore, was to evaluate the effect of various chelating solutions (EDTA- Apple Vinegar-sodium hypochlorite) on the radicular push out bond strength of Zinc oxide nanosealer and $\mathrm{AH}$ plus resin based root canal sealer.

\section{MATERIALS AND METHODS}

The crowns of all teeth were removed using a water-cooled, slow-speed diamond precision saw (Isomet 4000 Linear Precision Saw), so as to adjust the length of the roots to a standardized length of $16 \mathrm{~mm}$.

The root canals were prepared using ProTaper rotary instruments up to master apical rotary size F3 (\#30), in conjunction with $2 \mathrm{~mL}$ of Normal saline solution (Sodium Chloride $0.9 \%$ ) irrigation between each file and the chelating solution was applied for 1 minute then final rinse with distilled water.

The sealers were mixed as follow:

1- AHPlus (a paste-paste system) which is delivered in two tubes, the manufacturer instructions were followed to obtain a homogenous mix of the sealer.

2- ZOE Nanosealer (powder and liquid) the manufacturer instructions were followed to obtain a homogenous mix of the sealer
The sealers were loaded and introduced to the canal using K file size 40, the file was twirled counterclockwise, pumped up and down and wiped against the walls to apply the sealer all over canal wall.

Single cone obturation technique was used in this study (Protaper Gutta Percha point size F3.

On completion of instrumentation, the specimens was randomly divided into three groups ( $\mathrm{n}=60$ each) according to chelating solution applied:

Group (I) $1.5 \mathrm{~mL}$ of $17 \%$ EDTA $(\mathrm{pH}=7)$,

Group (II) $2.5 \mathrm{~mL}$ of vinegar apple,

Group (III) $2 \mathrm{~mL}$ of $5.25 \%$ sodium hypochlorite $(\mathrm{NaOCl})$.

In each group, the specimens were further randomly divided into two subgroups $(n=30)$ according to root canal sealer used:

Subgroup (a):AH Plus (DENTSPLY DeTrey GmbH, Konstanz, Germany)

Subgroup (b): Zinc oxide nanosealer

Specimens in the subgroups were further randomly divided into two groups $(n=15)$ according to storage time:

Subgroup (1): one week storage time.

Subgroup (2): one month storage time.

Each specimen was transversely sectioned perpendicular to the long axis of the root using a slow-speed diamond precision saw (Isomet 4000 Linear Precision Saw) to obtain a section $2 \mathrm{~mm}$ in thickness from the root thirds as measured using a digital calliper (Pachymeter, Electronic Digital Instruments, China).

\section{Push-out bond strength test:}

All specimens were exposed to the push-out test that was applied using The Instron universal testing machine.

Each section was coded and photographed from apical and coronal surfaces using a stereomicroscope 
(SZ-PT; Olympus, Tokyo, Japan) at an original magnification of $65 \mathrm{x}$. Calibration was performed by comparing an object of known length, a ruler in this study, using the "Set Scale" tool generated by the image analysis software (Image J; NIH, Bethesda, $\mathrm{MD})$.The diameter of the filling was then measured and the radius was calculated.

Each root slice was mounted in custom made loading fixture [metallic block with circular cavity at the middle, this cavity for specimen housing having a central whole to facilitate displacement of extruded filling material], then subjected to compressive loading at a crosshead speed of $1 \mathrm{~mm} / \mathrm{min}$ via a computer controlled materials testing machine (Model 3345; Instron Industrial Products, Norwood, MA, USA).

Load applied by a plunger of $(0.8 \mathrm{~mm}$ diameter $)$ corresponding to the radicular third (middle) to be tested. The plunger tip was sized and positioned to touch only the filling, without stressing the surrounding dentin, in apical coronal direction to push the filling toward the larger diameter, thus avoiding any limitation to the filling movement possibly owing to the canal taper. This way, it was guaranteed that the overlaying dentin was sufficiently supported during the loading process.The maximum failure load was recorded in Newton and converted into Mpa.

The bond strength was calculated from the recorded peak load divided by the computed surface area as calculated by the following formula.
$[\mathrm{A}=(3.14 \mathrm{x}$ r1X $3.14 \mathrm{x}$ r2) L],

Where

$\mathrm{r} 1$ apical radius, $\mathrm{r} 2$ coronal one,

$\mathrm{L}=[(\mathrm{r} 1-\mathrm{r} 2) 2+\mathrm{h} 2] 0.5$

and $\mathrm{h}$ is the thickness of the sample in millimetres].

Failure was manifested by extrusion of filling piece from root canal and was confirmed by sudden drop along load-deflection curve recorded by Nexygen computer software.

\section{RESULTS}

Comparing all Ah-plus subgroups using ANOVA test revealed a significant difference $(\mathrm{p}<0.0001)$, where the greatest mean value was recorded in (EDTA+AH Plus) group at 1 week storage time group (Ia1), while the lowest value was recorded at 1 month using (apple vinegar+AH Plus) group (IIa2). (Table 1)

Comparing all $\mathrm{ZnO}$ subgroups using ANOVA test revealed a significant difference $(p<0.0001)$, where the greatest mean value was recorded in (apple vinegar $+\mathrm{ZnO}$ nanosealer) group (IIb2) at 1 month storage time, while the lowest value was recorded at 1 week in ( $\mathrm{NAOCl}+\mathrm{ZnO}$ nanosealer) group (IIIb1). (Table 2)

Using different agents, the greatest mean value was recorded in ( EDTA+AH Plus) (1 week)

Table (1) Comparison of Mean and SD of Push-out stresses (MPA) using different agents in Ah-plus group at different storage time (ANOVA test)

\begin{tabular}{|c|c|c|c|c|c|c|}
\hline Group & \multicolumn{6}{|c|}{ Ah-plus } \\
\hline Agent & \multicolumn{2}{|c|}{ Apple vinegar } & \multicolumn{2}{|c|}{ EDTA } & \multicolumn{2}{|c|}{$\mathrm{NaOCl}$} \\
\hline Storage time & $1 \mathrm{~W}$ & $1 \mathrm{M}$ & $1 \mathrm{~W}$ & $1 \mathrm{M}$ & $1 \mathrm{~W}$ & $1 \mathrm{M}$ \\
\hline Mean & $1.263^{\mathrm{c}}$ & $0808^{\mathrm{d}}$ & $3.424^{\mathrm{a}}$ & $1.905^{\mathrm{b}}$ & $1.179^{\mathrm{c}}$ & $1.873^{\mathrm{b}}$ \\
\hline SD & 0.189 & 0.679 & 0.870 & 0.31 & 0.395 & 0.688 \\
\hline F value & \multicolumn{6}{|c|}{39.032} \\
\hline$P$ value & \multicolumn{6}{|c|}{$<0.0001^{*}$} \\
\hline
\end{tabular}

*significant at $p<0.05$, Tukey's post hoc test: means sharing the same superscript letter are not significantly different W: week, M: month 
group(Ia1), while the lowest mean was recorded in (Apple Vinegar $+\mathrm{ZnO}$ nanosealer) (1 week) group
(IIb1). ANOVA test revealed that the difference was statistically significant $(\mathrm{p}<0.0001)$ (Table 3)

Table(2): Comparison of Mean and SD of Push-out stresses MPA using different agents in ZnO group at different storage time (ANOVA test)

\begin{tabular}{|c|c|c|c|c|c|c|}
\hline Group & \multicolumn{6}{|c|}{$\mathrm{ZnO}$} \\
\hline Agent & \multicolumn{2}{|c|}{ Apple vinegar } & \multicolumn{2}{|c|}{ EDTA } & \multicolumn{2}{|c|}{$\mathrm{NaOCl}$} \\
\hline Storage time & $1 \mathrm{~W}$ & $1 \mathrm{M}$ & $1 \mathrm{~W}$ & $1 \mathrm{M}$ & $1 \mathrm{~W}$ & $1 \mathrm{M}$ \\
\hline Mean & $0.451^{\mathrm{c}, \mathrm{d}}$ & $1.258^{\mathrm{a}}$ & $0.362^{\mathrm{d}}$ & $0.72^{\mathrm{b}}$ & $0.216^{\mathrm{e}}$ & $0.575^{\mathrm{c}}$ \\
\hline SD & 0.061 & 0.41 & 0.136 & 0.296 & 0.183 & 0.182 \\
\hline F value & \multicolumn{6}{|c|}{35.22} \\
\hline P value & \multicolumn{6}{|c|}{$<0.0001^{*}$} \\
\hline
\end{tabular}

*significant at $p<0.05$, Tukey's post hoc test: means sharing the same superscript letter are not significantly different W: week, M: month

Table (3) Comparison of Mean and SD of Push-out stresses (MPA) using different agents in both groups (ANOVA test)

\begin{tabular}{|c|c|c|c|c|c|c|c|c|c|c|c|c|}
\hline Group & \multicolumn{6}{|c|}{ Ah-plus } & \multicolumn{6}{|c|}{$\mathrm{ZnO}$} \\
\hline Agent & \multicolumn{2}{|c|}{ Apple vinegar } & \multicolumn{2}{|c|}{ EDTA } & \multicolumn{2}{|c|}{$\mathrm{NaOCl}$} & \multicolumn{2}{|c|}{ Apple vinegar } & \multicolumn{2}{|c|}{ EDTA } & \multicolumn{2}{|c|}{$\mathrm{NaOCl}$} \\
\hline Storage time & $1 \mathrm{~W}$ & $1 \mathrm{M}$ & $1 \mathrm{~W}$ & $1 \mathrm{M}$ & $1 \mathrm{~W}$ & $1 \mathrm{M}$ & $1 \mathrm{~W}$ & $1 \mathrm{M}$ & $1 \mathrm{~W}$ & $1 \mathrm{M}$ & $1 \mathrm{~W}$ & $1 \mathrm{M}$ \\
\hline Mean & $1.263^{\mathrm{c}}$ & $0.808^{\mathrm{d}}$ & $3.424^{\mathrm{a}}$ & $1.905^{\mathrm{b}}$ & $1.179^{\mathrm{c}}$ & $1.873^{\mathrm{b}}$ & $0.451^{\mathrm{e}, \mathrm{f}}$ & $1.258^{\mathrm{c}}$ & $0.362^{\mathrm{f}}$ & $0.72^{\mathrm{d}}$ & $0.216^{\mathrm{g}}$ & $0.575^{\mathrm{e}}$ \\
\hline SD & 0.189 & 0.679 & 0.870 & 0.31 & 0.395 & 0.688 & 0.061 & 0.41 & 0.136 & 0.296 & 0.183 & 0.182 \\
\hline F value & \multicolumn{12}{|c|}{44.12} \\
\hline$P$ value & \multicolumn{12}{|c|}{$<0.0001^{*}$} \\
\hline
\end{tabular}

*significant at $p<0.05$,Tukey's post hoc test: means sharing the same superscript letter are not significantly different W: week, M: month

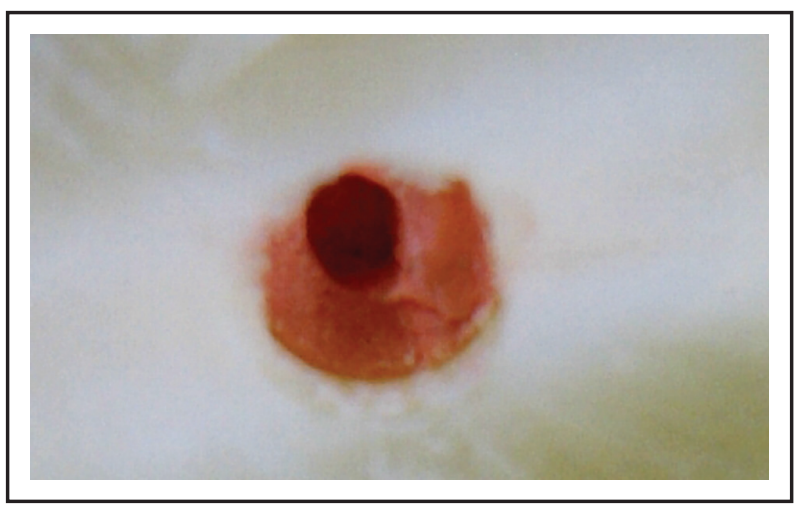

Cohesive failure group(Ia1)

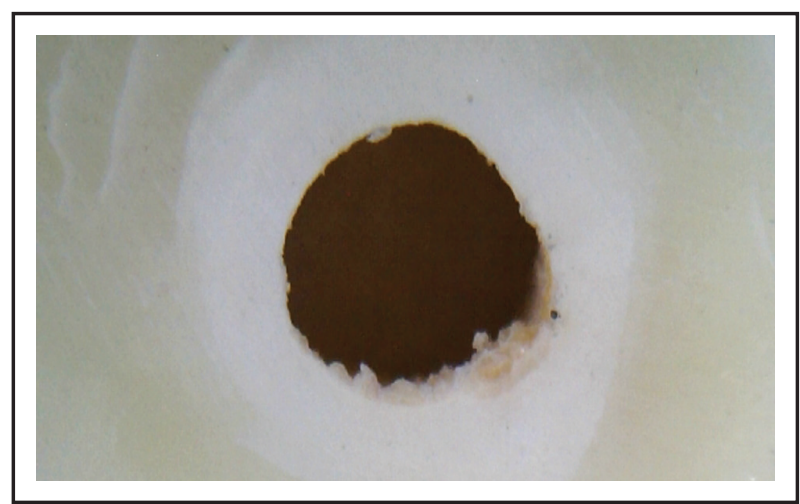

Adhesive failure group(Ib1) 


\section{DISCCUSION}

Complete obturation of the root canal system with an impervious, biocompatible and dimensionally stable filling material is essential for successful root canal treatment. ${ }^{(20)}$ Many root canal sealers have been developed to fill residual gaps between the individual gutta-percha points and between the gutta-percha and the canal wall.

At present, sealers based on epoxy resins afford very good physical properties and ensure adequate biological performance. Excellent apical sealing has been found with epoxy resin-based sealers. (21,22) Previous studies showed that the epoxy resinbased root canal sealer AH plus is cytocompatible ${ }^{(23)}$, biocompatible and has good tissue tolerance ${ }^{(24)}$, long-term dimensional stability ${ }^{(25)}$ and good sealing ability. ${ }^{(26,27)}$

Nano-technology and nano-materials have become an extremely active field of research in the last decade because of their potential application in different areas like medicine, information technologies, energy storage etc., nano-technologies have been used in the production of a wide range of dental materials in nano-dimensions by re-location and re-arrangement of atoms to prepare materials with better properties. Presence of very small particles leads to superior properties of the material. These unique properties, which are the subject of quantum mechanics, have attracted a great deal of interest ${ }^{(28)}$. So in this study we use ZOE nanosealer which is similar to various ZOE-based sealers, but with different sizes of nano-particles of zinc oxide.

However, the adhesion of a root canal sealer may be influenced by many factors, amongst them the presence of smear layer which is a negative factor in root canal sealing, because it forms an interface between the sealing material and the root canal walls, thus reducing adhesion. ${ }^{(29)}$ Different chemical solutions have been recommended for use with instrumentation of root canals to remove debris, smear layer and disinfect the root canal. So chelating agents have been recommended as adjuvant in root canal treatment as they are able to remove the inorganic component of smear layer the most com- mon chelating solutions are based on ethylenediamine tetra acetic acid (EDTA), which is used alternatingly with $\mathrm{NaOCl}$ solution to remove the smear layer. Also Apple Vinegar associates a good capacity to remove smear layer from the dentinal tubule entrances.

The effect of EDTA on the dentinal tissue structure and the smear layer removal capacity after 1 and $10 \mathrm{~min}$ of application was verified ${ }^{(30)}$.The chelating agent satisfactorily removed the smear layer in $1 \mathrm{~min}$, but it caused excessive erosion of peri- and intertubular dentin when applied for $10 \mathrm{~min}$.So in this study the chelating solution was applied for 1 minute then final rinse with distilled water.

The adhesion property has been studied on the basis of the expirmental model proposed and improved by using the universal testing machine to standardize the test, making it reproducible and more reliable ${ }^{(31)}$

The push-out test is based on the shear stress at the interface between dentin and cement which is comparable with stresses under clinical conditions. ${ }^{(32)}$

The finding of the conducted study revealed a significant difference whereas the highest mean value in all AH Plus subgroups was found in EDTA group at 1 week storage time, while the lowest value was recorded at 1 month using apple vinegar, these results corroborated other studied ${ }^{(7,8,16)}$ as the use of $17 \%$ EDTA as a final rinse could better facilitate exposure of the collagen network and render the dentin substrate more conducive to bonding of $\mathrm{AH}$ Plus sealer, which can adhere to the organic phase of radicular dentin ${ }^{(33)}$. While others found that there is no statistical difference between 17\% EDTA solution and apple vinegar solution on smear layer removal by using SEM evaluation ${ }^{(34)}$.

Comparing all $\mathrm{ZnO}$ subgroups revealed a significant difference, where the greatest mean value was recorded in apple vinegar group at 1 month storage time, while the lowest value was recorded at 1 week using $\mathrm{NAOCl}$.And the effectiveness of smear layer removal by apple vinegar is in agreement with some 
studies who was concluded that the apple vinegar associated or not with EDTA was more effective in removing smear layer from the root canals than $\mathrm{NaOCl}$ associated with EDTA. ${ }^{(35)}$ Also Since malic acid is present in the composition of apple vinegar, the results of the present study are consistent with other studies, who investigated the smear layer removal capacity of malic acid and found significantly better results than EDTA associated with $5.25 \%$ $\mathrm{NaOCl} .^{(36,37)}$

Also the lowest mean value of $\mathrm{NaOCl}$ is because of despite its excellent antimicrobial potential and ability to dissolve organic tissues; it is only ineffective in removing the smear layer ${ }^{(38)}$.

At both one week and one month storage time, a greater mean value was recorded in the AH-plus group using the different agents. This is probably because AH Plus had greater adhesion to root dentin than nano ZOE. This is likely due to the fact that, AH Plus (epoxy resin based sealer )has better penetration into the microirregularities because of it's creep capacity, long setting time and high flow rate which increases the mechanical interlocking between sealer and root dentin. This fact allied to the cohesion among sealer molecules, increases the resistance to removal and /or displacement from dentin which can be translated as greater adhesion ${ }^{(39)}$.

\section{CONCLUSION}

Within limits of the current study, we can conclude the following:

1- The epoxy resin- based (AH Plus) sealer when used with EDTA chelating agent had the highest push-out bond strength to intraradicular dentin compared to other chelating solutions (Apple vinegar and $\mathrm{NaOCl}$ ).

2- The nano ZOE sealer when used with apple vinegar chelating agent had the highest push-out bond strength to intraradicular dentin compared to other chelating solutions ( EDTA and $\mathrm{NaOCl}$ ).

3- All AH Plus sealer subgroups had higher pushout bond strength to intraradicular dentin compared to all nano ZOE sealer subgroups.

\section{REFRENCES}

1- Grandini S, Balleri P, Ferrari M. Evaluation of Glyde File Prepin combination with sodium hypochlorite as a root canal irrigant. J Endod ,2002;28:300-3.

2- Scelza MF, Pierro VS, Chagas MA, Silva LE, Scelza P. Evaluation of inflammatory response of EDTA, EDTA-T, and citric acid in animal model. Int Endod J, 2010;36:515-9.

3- Eick JD, Wilko RA, Anderson CH, Sorensen SE. Scanning electron microscopy of cut tooth surfaces and identification of debris by use of the electron microprobe. J Dent Res ,1970;49:59-68.

4- Brännström M, Johnson G. Effects of various conditioners and cleaning agents on prepared dentin surfaces: a scanning electron microscopic investigation. J Prosth Dent., 1974; 31, 422-30.

5- Marending M, Paqué F, Fisher J, Zehnder M. Impact of irrigant sequence mechanical properties of human root dentin. J Endod. ,2007; 1325-1328-3

6- Sirtes G, Waltimo T, Schaetzle M, Zehnder M. The effects of temperature on sodium hypochlorite short-term stability, pulp dissolution capacity, and antimicrobial efficacy. J Endod. ,2005;31:669-671.

7- Torabinejad M, Handysides R, Khademi A, Bakland L. Clinical implications of the smear layer in endodontics: a review. Oral Surg Oral Med Oral Patho Oral Radio Endod., 2002; 94:658-66.

8- Shahravan A, Haghdoost AA, Adl A, Rahimi H, Shadifar F. Effect of smear layer on sealing ability of canal obturation: A systematic review and meta-analysis. J Endod, 2007;33:96-105.

9- Costa D, Dalmina F, Irala L. The use of the vinegar as a chemical auxiliary in endodontics: a literature review. Rev Sul-Bras Odontol. 2009; 6:185-193.

10- Estrela C, Lopes H, Elias C, Leles C, Pécora J. Surface cleaning of root canal by apple vinegar, sodium hypochlorite , chlorohixidine and EDTA. Rev Assoc Paul Cir Dent., 2007; 61:117-22

11- Estrela C, Estrela C, Cruz-Filho A, Pécora J. ESP substance: option in endodontic therapeutic. J Bras Endod,2005;5:273-9.

12- Spanó J, Silva R, Guedes D, Sousa-Neto M, Estrela C, Pécora J. Atomic absorption spectrometry and scanning electron microscopy evaluation of concentration of calcium ions and smear layer removal with root canal chelators. J Endod ,2009;35:727-30. 
13- Caligiani A, Acquotti D, Palla G, Bocchi V. Identification and quantification of the main organic components of vinegars by high resolution $1 \mathrm{H}$ NMR spectroscopy. Analyt Chim Acta, 2007 ;585:110-9.

14- Carvalho-Junior J, Guimarães L, Correr-Sobrinho L, Pecora J, Sousa-Neto M Evaluation of solubility, disintegration, and dimensional alterations of a glass ionomer root canal sealer. Braz Dent J. ,2003, 114:118-14

15- Sousa-Neto M, Passarinho-Neto J, Carvalho-Junior J, Cruz-Filho A, Pecora J, Saquy P Evaluation of the effect of EDTA, EGTA and CDTA on dentin adhesiveness and microleakage with different root canal sealers. Braz Dent J, 2002, 123:128-13.

16- Tagger M, Tagger E, Tjan A, Bakland L Measurement of adhesion of endodontic sealers to dentin. J Endod , 2002, 351:354-28

17- Camps J, Pommel L, Bukiet F, About I. Influence of the powder/liquid ratio on the properties of zinc oxide-eugenol-based root canal sealers. Dent Mater. ,2004;20:915-23.

18- Takatsuka T, Tanaka K, Iijima Y. Inhibition of dentine demineralization by zinc oxide: In vitro and in situ studies. Dent Mater. ,2005;21:1170-7.

19- Wong RH, Palamara JE, Wilson PR, Reynolds EC, Burrow MF. Effect of CPP-ACP addition on physical properties of zinc oxide non-eugenol temporary cements. Dent Mater. ,2011;27 : 329-38

20- Ahlberg K, Tay W. A methacrylate-based cement used as a root canal sealer. Int Endo J. ,1998;31: 15-5.

21- Grossman L. Physical properties of root canal cements. J Endod, 1976;2: 166.

22- Limkangwalmongkol S, Abbott P, Sandler A. Apical dye penetration with four root canal sealers and gutta-percha using longitudinal sectioning. J Endod. 1992;18: 535-16.

23- Leyhausen G, Heil J, Reifferscheid G, Waldmann P, Geurtsen W. Genotoxicity and cytotoxicity of the epoxy resin-based root canal sealer AH plus. J Endod. 1999;25: 109-8.

24- Leonardo M, Silva L, Almeida W, Utrilla L. Tissue response to an epoxy resin-based root canal sealer. Endod Dent Traumatol. 1999; 15:28-4.

25- Al-Khatar N, Kunzelmann K, Hickel R. Apical leakage of new root canal sealers (abstract). J Dent Res. 1995;74: 945-12.

26- De Almeida W, Leonardo M, Tanomaru Filho M, Silva L.
Evaluation of apical sealing of three endodontic sealers. Int Endod J. 2000;33: 25-4.

27- Miletic I, Ribaric S, Karlovic Z, Silvana J, Bosnjac A, Anic I. Apical leakage of five root canal sealers after one year of storage. J Endod. 2002;28: 431-5.

28- Abramovitz I, Weinberg G, Borenstein A, Polak D, KeslerShvero D, et al. InVitro Biocompatibility of Endodontic Sealers Incorporating Antibacterial Nanoparticles. journal of nanomaterials. 2012;69:72-15.

29- Kennedy W, Walker W, Gouch R Smear layer removal effects on apical leakage. J Endod, 1986 ;12: 21-7.

30- Çalt S, Serper A. Time dependent effects of EDTA on dentin structures. J Endod 2002;28:17-9.

31- Grossman D, Louis 1 ,Dm D physical properties of root canal cements. J Endod 1976;166:175-6.

32- Qrastavik D, Eriksen H, Beyer-O. Adhesive properties and leakage of root canal sealer in vivo. Int Endod J 1983; 16:59-63.

33- Tagger M, Tagger E, Tjan A, Bakland L. shearing bond strength on endodontic sealers to gutta percha .J Endod $2003 ; 249: 51-5$.

34- Saleh I, Ruyter I, Haapasalo P, Orstavik D. Adhesion of endodontic sealers:scanning electron microscopy and energy dispersive spectroscopy . J Endod 2003;29:595-1.

35- Neelakantan P, Varughese A, Sharma S, Subbarao C, Zehnder M, De-Deus G. Continuous chelation irrigation improves the adhesion of epoxy resin-based root canal sealer to root dentine. Int Endod J. 2012 ;1097:102-12

36- Palaniswamy U, Kaushik M, Ram Surender L, Prashar N, Shikha Arya S, Srikanth Pasari S. A SEM evaluation of smear layer removal using two rotary instrument systems with EDTA and vinegar as a root canal irrigant. Journal of Restorative Dentistry 2016;41:17-21.

37- Candeiro G, de Matosa I, da Costa C, Fonteles C, do Vale M .A comparative scanning electron microscopy evaluation of smear layer removal with apple vinegar and NaOCL associated with EDTA. J Appl Oral Sci 2011; 1678-7757-4

38- Baumgartner JC, Mader CL. A scanning electron microscopic evaluation of four root canal irrigation regimens. J Endod ,1987; 147:57-13

39- Leonardo M, Silva L, Almeida W, Utrilla L.Tissue response to an epoxy resin-based root canal sealer. Endodont Dent Traumatol. 1999;15: 28-44 